\title{
Evaluation of Waste Plastic Pyrolysis Oil Performance with Diethyl Ether Additive on Insulated Piston Diesel Engine
}

\author{
S. Padmanabhan*†, C. Joel**, Linda Joel***, Obulareddy Yuvatejeswar Reddy*, K.G.D. Sri Harsha* and \\ S. Ganesan**** \\ *School of Mechanical and Construction, Vel Tech Rangarajan Dr. Sagunthala R\&D Institute of Science and Technology, \\ Chennai, India \\ ***Department of Mechanical Engineering, Easwari Engineering College, Chennai, India \\ ***Department of Mathematics, SRM Institute of Science and Technology, Ramapuram, Chennai, India \\ ****Department of Mechanical Engineering, Sathyabama Institute of Science and Technology, Chennai, India \\ $\dagger$ Corresponding author: S. Padmanabhan; padmanabhan.ks@ gmail.com
}

Nat. Env. \& Poll. Tech.

Website: www.neptjournal.com

Received: 21-05-2021

Revised: 24-06-2021

Accepted: 04-07-2021

Key Words:

Thermal barrier coating

Coated piston

Diethyl ether

Diesel engine

Waste plastic pyrolysis oil

\section{ABSTRACT}

Considering the amount of waste plastics has risen significantly, energy may be extracted from it. Not only is it possible to dispose of waste plastics by converting them to fuel, but it is also possible to extract energy from them. Our research is motivated by the prospect of using waste plastics as a source of energy through waste plastic pyrolysis oil (WPPO). The innovation of this research is that it will assess the efficiency of plastic pyrolysis oil derived from Low-Density Polyethylene (LDPE) on a Thermal Barrier Coated (TBC) piston engine. The incremental ratio of WPPO to pure diesel with the addition of diethyl ether (DEE) was determined and its output and exhaust emission standards were evaluated using a direct injection single cylinder low heat rejection diesel engine. The results for the WPPO blends were promising as with TBCW20DEE10 demonstrating a 5 to $15 \%$ increase in carbon monoxide under different load conditions. TBCW20DEE10 confirmed a greater reduction of hydrocarbons varying from 5 to $12 \%$. At half load condition, TBCW20DEE10 emits approximately $3.5 \%$ less unit of smoke.

\section{INTRODUCTION}

The world's use of plastics is increasing daily, and the world is yet to discover a suitable substitute. Disposal of plastic products after use poses a significant risk. The most environmentally friendly way to dispose of waste plastics is to turn them into energy fuel. Rajan et al. (2016) examined the efficiency and combustion characteristics of a diesel engine fueled by recycled plastics. The results indicated that the engine would run on waste plastic oil and its mixtures without modification can be used as a substitute for diesel fuel. Gungor et al. (2015) analyzed waste plastic oil and contrasted it to fuel in a multi-cylinder diesel engine. Thermal performance significantly decreased when pure WPPO was used. The concentrations of carbon monoxide and nitrogen oxides increased.

Mangesh et al. (2017) conducted an exhaustive analysis of waste plastic oil conversion methodology, research, and property characteristics, resulting in a greater understanding of waste plastic oil fuel conversion as an alternate fuel. Bridjesh et al. (2018) made an effort to replace diesel with half the amount of WPPO and the additives diethyl ether and methoxyethyl acetate. Sachuthananthan et al. (2019) combined different ratios of magnesium oxide nanoparticles with plastic pyrolysis oil. The investigation was conducted to determine the effect of compression ignition on the physicochemical properties of the engine. Singh et al. (2020) developed pure plastic pyrolytic oil without using a catalyst and analyzed the fuel properties. The plastic oil blends were checked on the engine and it was determined that using $50 \%$ blends results in a marginal loss of performance and a nominal rise in emissions. Mani et al. (2011) investigated the oxidation of plastic oil in a diesel engine. It has been compared to the performance of diesel engines. The exhaustive pollution findings demonstrated a greater spectrum of emissions than standard diesel.

Mangesh et al. (2020b) investigated a novel method for converting unsaturated compounds to saturated compounds through pyrolysis oil hydrogenation. The research investigated the combustion, production, and emission of hydrogenated polypropylene pyrolysis oil mixed with diesel. Das et al. (2020) investigated the performance and emission of a single-cylinder DI four-stroke diesel engine using waste plastic oil (WPO) derived from pyrolysis of waste plastics using Zeolite-A as the catalyst. The engine study revealed improved brake thermal performance up to $20 \%$ blends at full load. The NOx and 
$\mathrm{HC}$ emission is found lower under low load conditions and became higher by increasing the load as compared to diesel. Fuel exergy was significantly increasing after blending WPO with pure diesel, but the exergetic efficiency of the blended fuels followed the reverse trend. However, an increase in load of the engine improved the exergetic efficiency. Hariram et al. (2017) contrasted the properties of plastic pyrolysis oil to those of diesel and also tabulated the properties of blended fuels containing cetane and ethanol. Damodharan et al. (2017) found that the addition of $n$-butanol reduced diesel pollution while increasing $\mathrm{HC}$ emission. Due to the inclusion of $10 \%$ n-butanol by volume in comparison to WPPO and diesel, the WPPO blend reduces NOx pollution significantly. However, NOx emissions from higher volume n-butanol blends exceeded the applicable WPPO.

Sivakumar and Bridjesh (2019) and Sambandam et al. (2020) had used a low-heat diesel engine with blended waste plastic oil. WPPO's low-heat engine has proven to have stronger performance than diesel but for NOx emissions. Gnanamoorthi and Jayaram (2018) observed an improvement in frequency thermal performance and a decrease in real fuel consumption for diesel engines covered by thermal barriers. With the exception of hydrocarbon emissions, there was a significant reduction in nitrogen oxide and carbon monoxide emissions with a coated engine. Ramalingam et al. (2016) conducted a preventative study in a diesel engine using copper and cadmium nanocatalyst coated pistons, as contrasted to an uncoated engine. The results showed that a coated piston reduced nitrogen oxide, carbon monoxide, and hydrocarbon emissions significantly.

The primary objective of this study is to evaluate the feasibility of using WPPO as an alternate energy source in the automotive industry. To combat the high-value emissions of WPPO in a diesel engine, a thermal barrier coating on the combustion chamber components is highly desirable. The thermal barrier coated piston is used in this investigation on a single-cylinder diesel engine to evaluate waste plastic oil and to minimize exhaust pollution and increase engine performance, resulting in lower fuel consumption. The incremental ratio of WPPO with oxygenated additive DEE was blended with pure diesel for the experiment, and its output and exhaust emission standards were evaluated on the TBC piston engine.

\section{MATERIALS AND METHODS}

\section{Thermal Barrier Insulation}

Many researchers are actively innovating to boost engine efficiency by changing the engine components. The thermal barrier coating (TBC) on the combustion chamber components is a safer way of keeping heat resistant in the chamber to improve combustion efficiency. Coating materials should have a good thermal expansion coefficient to survive the heat shock during combustion (Patnaik et al. 2017). Thermal barrier coating engines are engines that reduce thermal rejection and recover combustion energy. Piston heat insulation has been incorporated into engines to further minimize heat loss during combustion and thereby improve the thermal performance of diesel engines. Ceramic insulation methods are gaining traction as the planet strives to meet stricter pollution standards while still saving money on diesel. Ceramic materials can exhibit desirable properties such as a strong coefficient of thermal expansion, a greater Poisson's ratio, low thermal conductivity, and a stable phase structure at elevated combustion temperatures (Sivakumar \& Senthil Kumar 2014). Among the various coating techniques, some researchers used the plasma spray coating method to avoid heat loss from high-temperature surroundings. Joel et al. (2018) evaluated piston coatings utilizing CAE methods rather than physical experiments. Zirconia and alumina stabilized with yttria are commonly utilized in thermal-barrier components, both of which were left unattended (Thibblin et al. 2018).

\section{Waste Plastic Pyrolysis Oil}

Catalytic pyrolysis may be used to convert used waste plastics into alternative energy fuel for diesel engines. The chemical properties of the plastic pyrolysis fuel vary according to the grade of used plastics and the pyrolysis process used. The low calorific value and excessive viscosity of the plastic pyrolysis oil are the primary drawbacks of using plastic oil as a diesel engine replacement. Mangesh et al. (2020a) studied the properties of four related pyrolysis oils derived from a variety of plastics, including high-density polyethylene, low-density polyethylene, polypropylene, and styrene.

Due to its affordability, Low-Density Polyethylene (LDPE) was used as a type of waste plastic in this study. LDPE is available in a variety of forms, which results in lower intermolecular resistance and, thus, lower tensile strength and stiffness as compared to High-Density Polyethylene (HDPE). Although polyethylene with a low density exhibits far greater elasticity than HDPE, its lateral branching results in a less crystalline shape. It is very resistant to water and is used in a variety of other applications, including garbage containers, garbage cans, covering paper, and packaging. These goods are widely used in daily life, so LDPE waste is collected daily to serve as the second-largest plastic waste stream in solid waste.

Table 1 summarizes the properties of waste plastic pyrolysis oil. WPPO's fuel properties are very close to those of diesel fuel in many critical respects. However, the formulated fuel's combustion and pollution properties must be determined. Additionally, very few experiments have been conducted on the behavior of plastic pyrolysis oil with additives in a thermal coated engine. The current article 
Table 1: Properties of waste plastic pyrolysis oil.

\begin{tabular}{|lllll|}
\hline Sl. No. & Properties & Diesel & WPPO & ASTM standards \\
\hline 1 & Calorific Value, $\mathrm{kcal} / \mathrm{kg}$ & 10952 & 11507 & ASTM D 240 \\
2 & Kinematic Viscosity at $40^{\circ} \mathrm{C}, \mathrm{cSt}$ & 2.59 & 4.89 & ASTM D 445 \\
3 & Density $@ 15^{\circ} \mathrm{C}, \mathrm{kg} / \mathrm{m}^{3}$ & 838 & 798 & ASTM D 1298 \\
4 & Flash Point,${ }^{\circ} \mathrm{C}$ & 74 & 23 & ASTM D 93 \\
5 & Fire Point,${ }^{\circ} \mathrm{C}$ & 85 & 32 & - \\
6 & Cetane Index & 53 & 65 & ASTM D 613 \\
\hline
\end{tabular}

discusses the usage of waste plastic oil derived from LDPE as a possible replacement fuel for existing diesel engines. As a result, the analysis is conducted using different fuel blend percentages and a coated piston to determine the efficiency, combustion, and emission characteristics.

\section{Experimental Details}

The engine investigation was evaluated using a constant speed single-cylinder water-cooled direct injection diesel engine with a power of $4.2 \mathrm{~kW}$. The hand-cranking method was used to start the test engine, and the diesel engine was connected to an eddy current dynamometer. A dynamometer can be used to manually load the engine from zero to maximum load in increments of $25 \%$ to $100 \%$, depending on the engine power generated. The test engine was permitted to run under normal test conditions. The engine spins at 1500 rpm and has an 18:1 compression ratio. The AVL di gas analyzer and AVL smoke meter were used to observe the exhaust pollution characteristics.
The use of WPPO was explored by engine efficiency and pollution characteristics measurements. The test was conducted using diesel as the baseline fuel. The blends were prepared on the volume based on $70 \%$ diesel and $20 \%$ of WPPO and $10 \%$ of DEE as TBCW20DEE10. Similarly, TBCW30DEE10 and TBCW40DEE10 were prepared with $30 \%$ and $40 \%$ WPPO volume for the testing. The test was carried out on a diesel engine with a coated piston using WPPO blend diesel. The gases emitted by the engines are determined, and they include unburned hydrocarbons (HC), carbon monoxide (CO), nitrogen oxides (NOx), and smoke.

\section{RESULTS AND DISCUSSION}

\section{Performance Characteristics}

Brake thermal efficiency: Engine output was determined by the brake thermal efficiency (Fig. 1). The thermal performance of the brakes is determined by the ratio of brake engine power to fuel energy, with fuel energy being

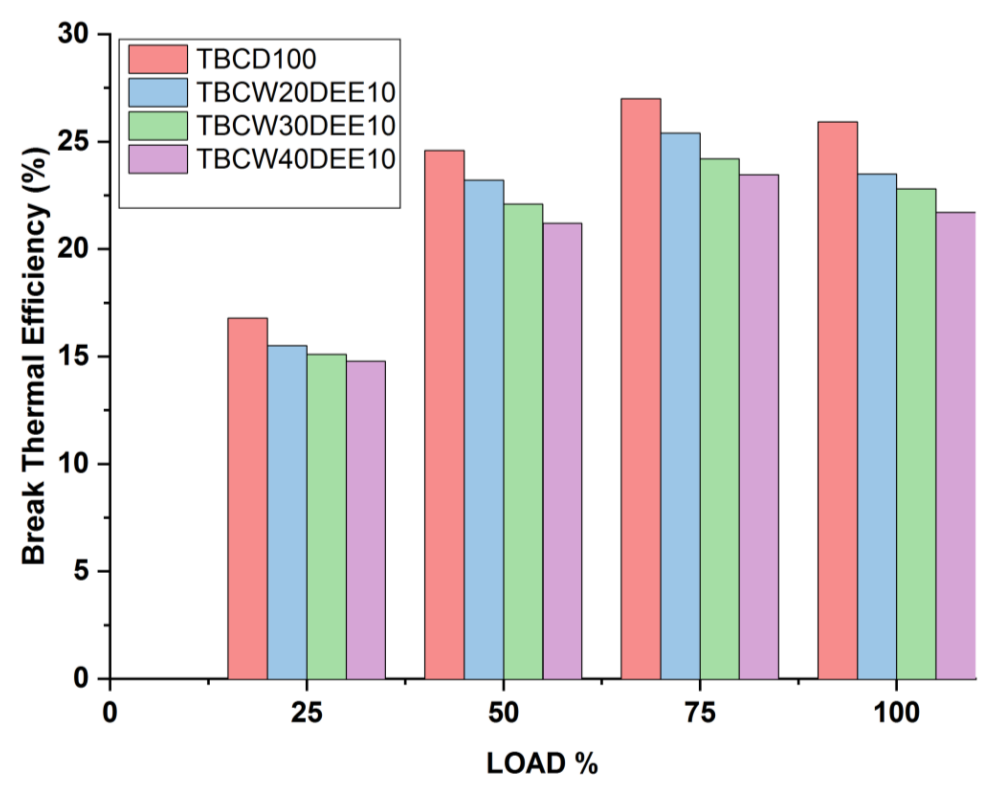

Fig. 1: Evaluation of WPPO's brake thermal efficiency on engine load. 
determined by fuel usage and the calorific benefit of fuel blends. At maximum load, the TBCW20DEE10 brake thermal efficiency increased and approached that of the TBCW30DEE10 brake thermal efficiency. A lower exhaust temperature indicates less heat loss during combustion, which results in a better thermal performance of the brakes. When comparing an uncoated TBC engine to one coated with unblended WPPO, similar findings of an increase in brake thermal performance at full load were discovered (Sivakumar $\&$ Bridjesh 2019).

WPPO exhibits up to an $80 \%$ increase in thermal performance at maximum load (Mani et al. 2011). Due to improved vaporization and air-fuel atomization, the TBC coated engine achieves higher thermal performance, maintains optimum in-cylinder temperatures, improves combustion efficiency, and maintains a consistent ignition pace. Additionally, the TBC coating reduces the reject rate of the combustion chamber, increasing the strength available to generate a unit $\mathrm{kW}$ for a limited volume of diesel, resulting in increased brake thermal performance.

Specific Fuel Consumption: The engine has a unique specific fuel consumption (SFC) value that varies with speed and load. For example, a reciprocating engine operates at full efficiency only when it absorbs unthrottled air and travels near its torque peak. However, only a few turbines were able to operate at optimum performance. Brake-specific fuel consumption falls by approximately $1.5 \%$ to $7.5 \%$ for TBCW20DEE10 at various load conditions as compared to TBCD100 as represented in Fig. 2. The coating combustion parts result in a shorter ignition delay time, which results in a lower SFC rating than a conventional diesel engine. SFC rises as the amount of blends containing WPPO increases. This is attributed to WPPO's low atomization owing to its increased viscosity and density.

\section{Emission Characteristics}

Unburned hydrocarbons: The majority of hydrocarbons emitted originate from a tested diesel, while others have changed structures as a result of chemical processes occurring within the combustion chamber. When the diesel engine is started or warmed up, $\mathrm{HC}$ emissions normally reach the maximum value due to vaporization, a slower oxidation rate, and the fuel mixture (Hariram et al. 2020). In Fig. 3, TBCW20DEE10 demonstrated a higher hydrocarbon reduction efficiency of $5 \%$ to $12 \%$, under different load conditions. Sivakumar and Bridjesh (2019) found that TBC engines emit less hydrocarbons than diesel engines due to the increased amount of heat produced inside the combustion chamber and the results of a ten ppm lower WPPO value than an

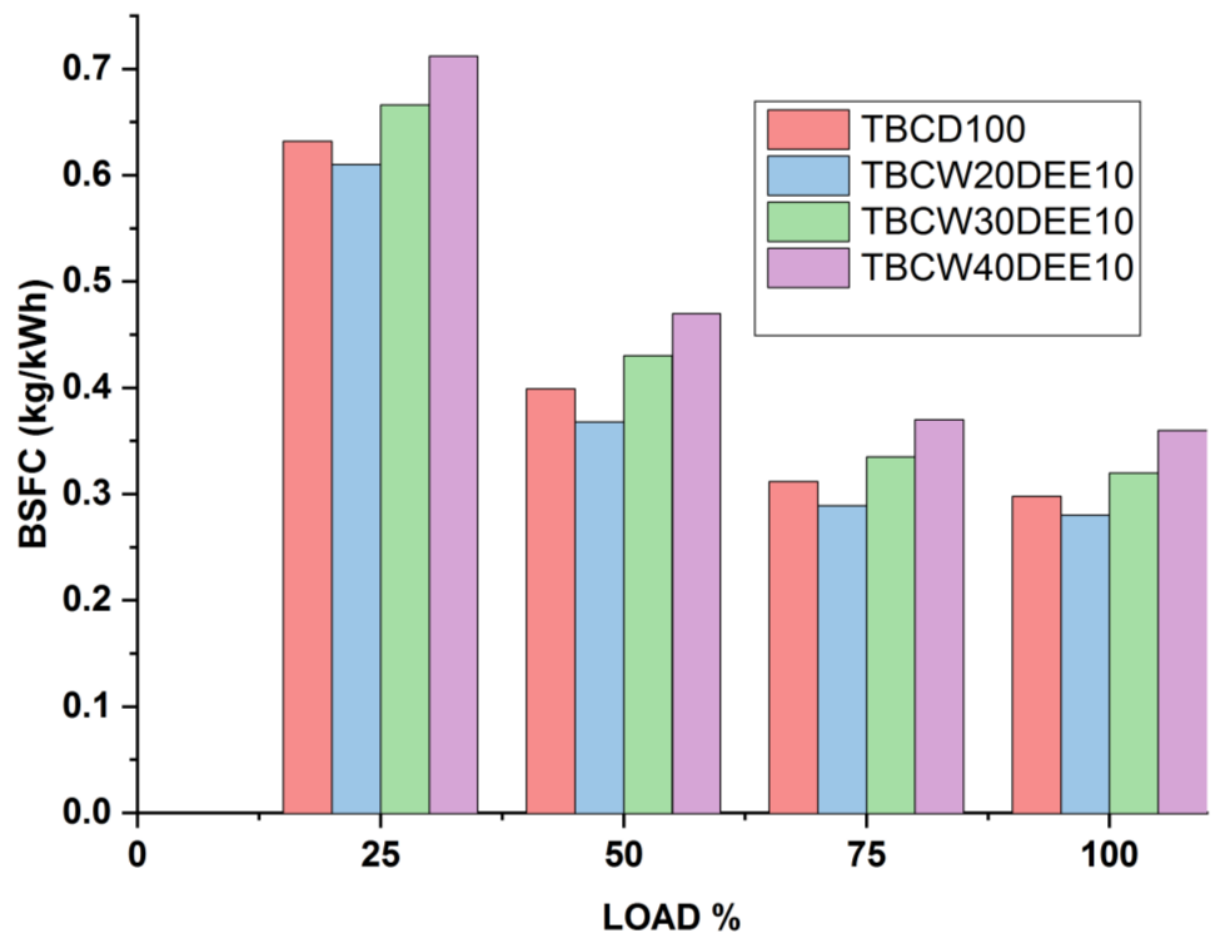

Fig. 2: Evaluation of WPPO's specific fuel consumption on engine load. 


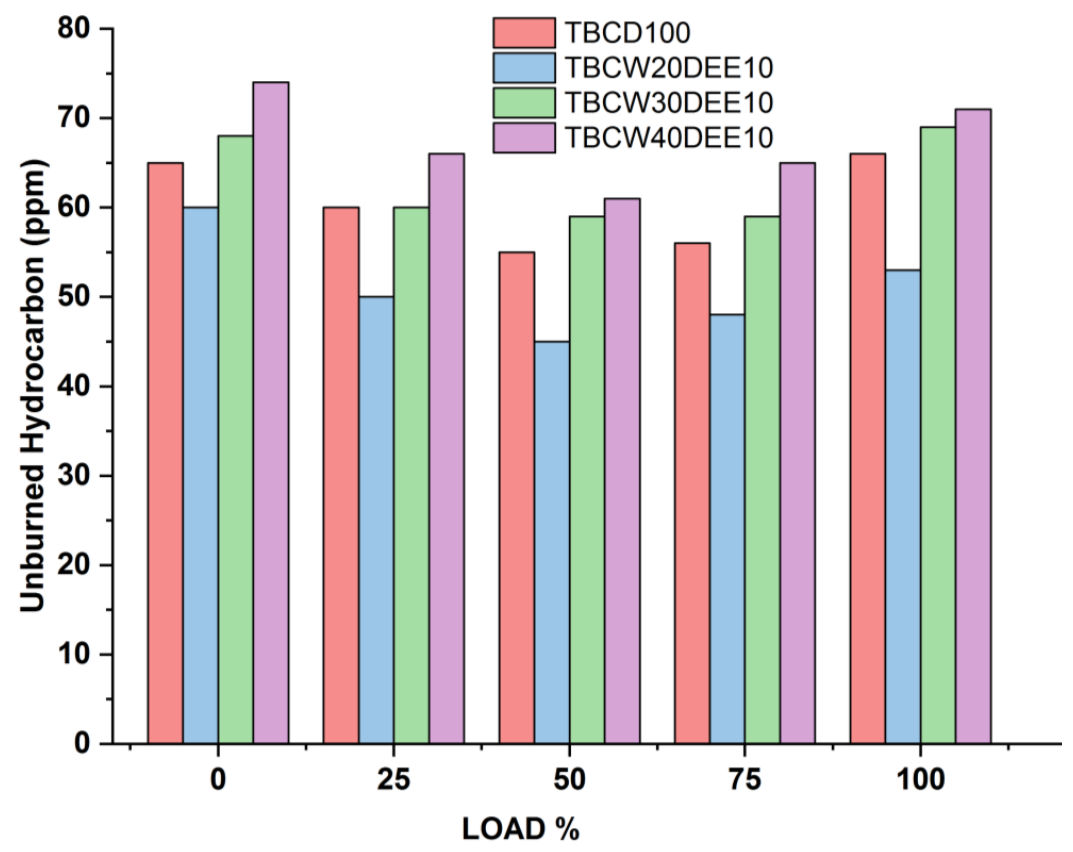

Fig. 3: Evaluation of WPPO's Unburned Hydrocarbons on engine load.

uncoated engine. As the percentage of WPPO increased, $\mathrm{HC}$ pollution increased as a result of incomplete combustion and unreacted hydrocarbons. The fuel blends do not extend out through the combustion chamber, and therefore do not burn down around the cylindrical wall or across crevices. The WPPO's low cetane number and reduced auto-ignition characteristics enhance the quenching impact in the leaner mixture area of the cylinder, which increases $\mathrm{HC}$ emissions. Additionally, unreactive hydrocarbons do not degrade into saturated compounds through combustion, which are released as exhaust (Singh et al. 2020). The indestructible essence of waste plastic is a product of the presence of unsaturated aromatic mixtures, which increases hydrocarbon emissions.

Carbon monoxide: Carbon Monoxide is formed as an intermediate compound during hydrocarbon combustion. The equivalence ratio proportions are the critical element in $\mathrm{CO}$ development. The elevated $\mathrm{CO}$ concentration is due to increased fuel intake at higher loads. The lower equivalence ratio, along with the increased in-cylinder temperatures, leads to extremely low $\mathrm{CO}$ emissions at initial loads. Carbon monoxide emission decreases gradually from low to half load and then increases sharply to maximum load for all the blends shown in Fig. 4. TBCW20DEE10 demonstrated an increase in carbon monoxide elimination of $5 \%$ and $15 \%$ under different load conditions. Sivakumar and Bridjesh (2019) discovered that TBC engines emit less $\mathrm{CO}$ at maximum load than traditional engines. WPPO contains about four percentage oxygen, which helps in full combustion and results in a greater decrease in carbon monoxide production. $\mathrm{CO}$ pollutants for the research fuel are reduced in the ceramic coated engine as opposed to the uncoated engine (Aydin et al. 2015).

Additionally, the TBC coating improves the combustion performance of WPPO mixtures by allowing for larger cylinders, which results in slightly increased cylinder pressure, combustion temperature, and air-fuel mixing, as well as oxygen quality. The higher fuel quantity used in combustion, along with the same amount of gas enclosed within a cylinder, results in a rich mixture that produces more $\mathrm{CO}$ emissions at maximum engine load. The primary cause of increased $\mathrm{CO}$ emissions is fuel-rich combustion inside the cylinder, which results in an insufficient evaporation period for the fuel mixture and an insufficient concentration of oxygen for combustion.

Nitrogen oxides: As shown in Fig. 5, all tested fuels exhibit a growing pattern in terms of NOx emission levels. Sivakumar and Bridjesh (2019) found increased NOx emissions in uncoated engines for WPPO and TBC diesel engines, with NOx emissions increasing more for WPPO. This is attributed to the use of larger cylinders and the melting of a thermal film coated with YSZ in the combustion chamber. Mani et al. (2011) found that waste plastic oil generated $25 \%$ more NOx as compared to pure diesel at maximum 


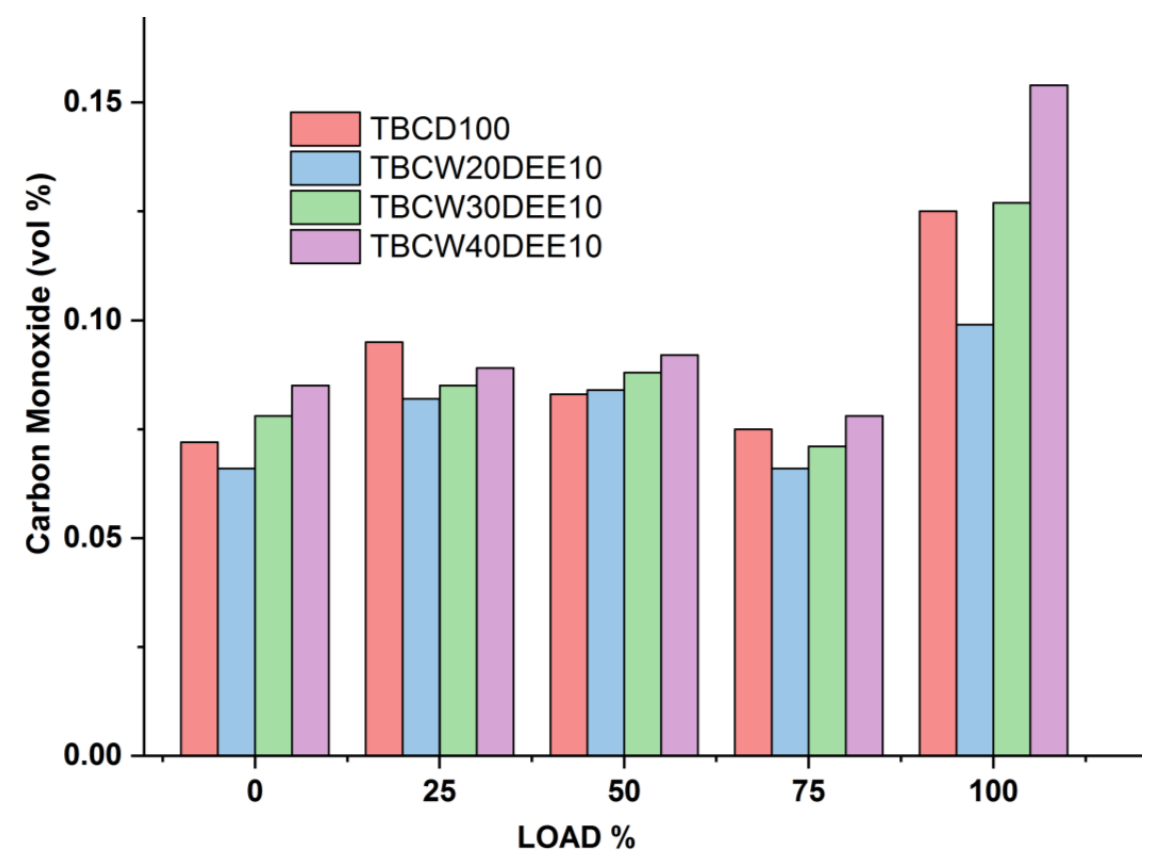

Fig. 4: Evaluation of WPPO's carbon monoxide on engine load.

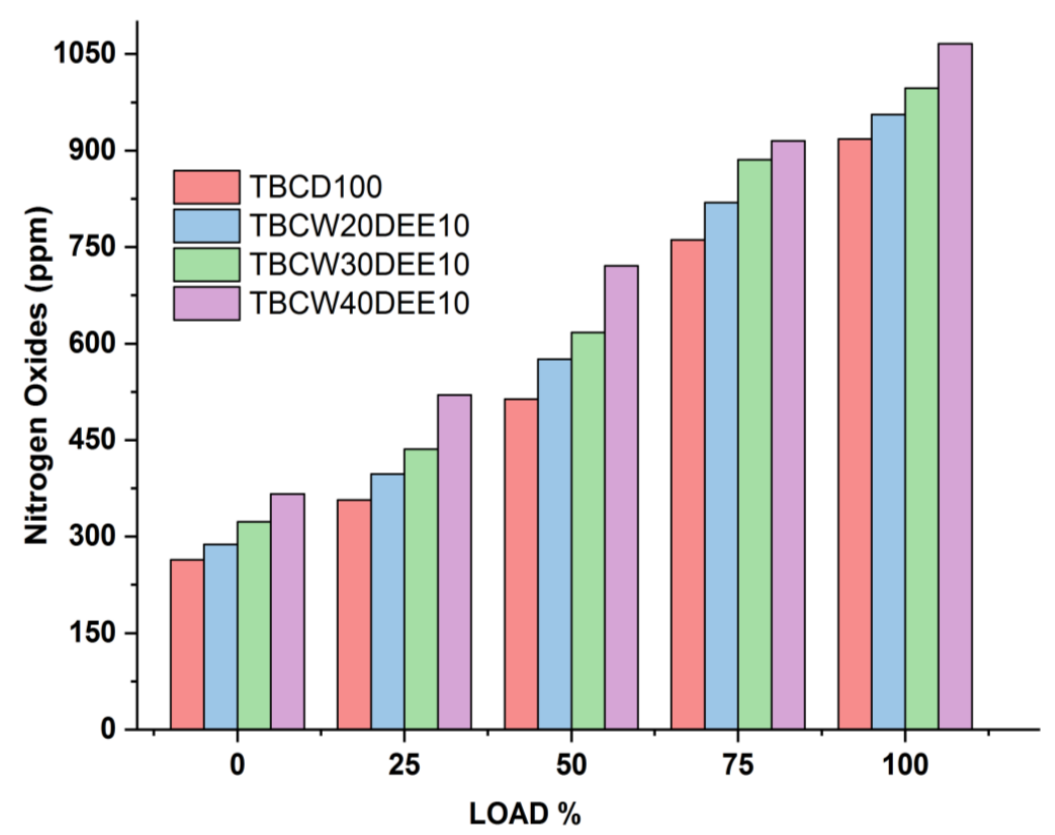

Fig. 5: Evaluation of WPPO's nitrogen oxides on engine load.

load. The primary factor contributing to NOx emission is the increased temperature within the cylinder and the overall peak temperature during the combustion cycle as a result of the lean fuel mixture (Hoang \& Pham 2019).
NOx development occurs only at the point of combustion termination at increased gas levels, as $\mathrm{N} 2$ reacts with $\mathrm{O} 2$ at these increased temperatures in the soil. $\mathrm{O} 2$ also plays a major part in the formation of NOx. 
When oxygen molecules appear at a lean mixing scale, NOx levels rise, resulting in higher combustion temperatures. The Zeldovich process undoubtedly governs the kinetics of NOx production, and some of the differences in NOx are due to oxygen concentration, combustion chamber temperature, surplus air coefficient, and residence time (Nam Cao et al. 2020). The combustion temperature, which increases NOx generation, is another variable that aids in the reaction between $\mathrm{N} 2$ and $\mathrm{O} 2$ molecules. Temperature, engine revolutions per minute, fuel mixture density, and combustion chamber homogeneity are only a few of the variables that influence NOx output.

Smoke emission: Smoke is formed in engines at the diffusion combustion period, where all the fuel atomized droplets are separated into elementary carbon atoms which are later oxidized in the combustion region. WPPO comprises a higher proportion of aromatic elements, it develops an inappropriate fuel mixture and forms a spray, resulting in incomplete combustion and significant smoke emission. Smoke concentrations often arise in the combustion-rich region due to a shortage of oxygen, a higher $\mathrm{C} / \mathrm{H}$ ratio, a higher viscosity of the fuel, insufficient atomization, and an unnecessary concentration of fuel inside the combustion chamber.
As shown in Fig. 6, TBCD100 emits less smoke than TBCW20DEE10, while TBCW20DEE10 emits approximately $3.5 \%$ less HSU smoke at half load. Sivakumar and Bridjesh (2019) found that TBC engines emit less smoke than traditional diesel engines due to the combustion chamber accumulating more heat. Mani et al. (2011) found that waste plastic oil generated $40 \%$ more smoke than pure diesel at maximum load. WPPO blends produce more smoke than diesel oil does. As a result, the engine cylinder does not receive a homogeneous charge. The explanation for the increased smoke strength is that the combustion time and flame spreading rate have been decreased. At full load, smoke production occurs as a result of insufficient oxygen and irregular combustion. The intensity difference in smoke is caused by a partial exhaust gas replacement caused by combustion instability. Increased hydrocarbon burning will result in full combustion and a reduction in smoke levels. Alternatively, increasing the fuel injection pressure results in improved atomization of the fuel blends, resulting in complete, safer combustion and a decrease in smoke (Nam Cao et al. 2020). The inclusion of TBC laminates mitigates the negative consequences by raising cylinder temperature and thereby reducing ignition centers and smoke, which is the product of the diesel blend's larger mean droplet size being broken.

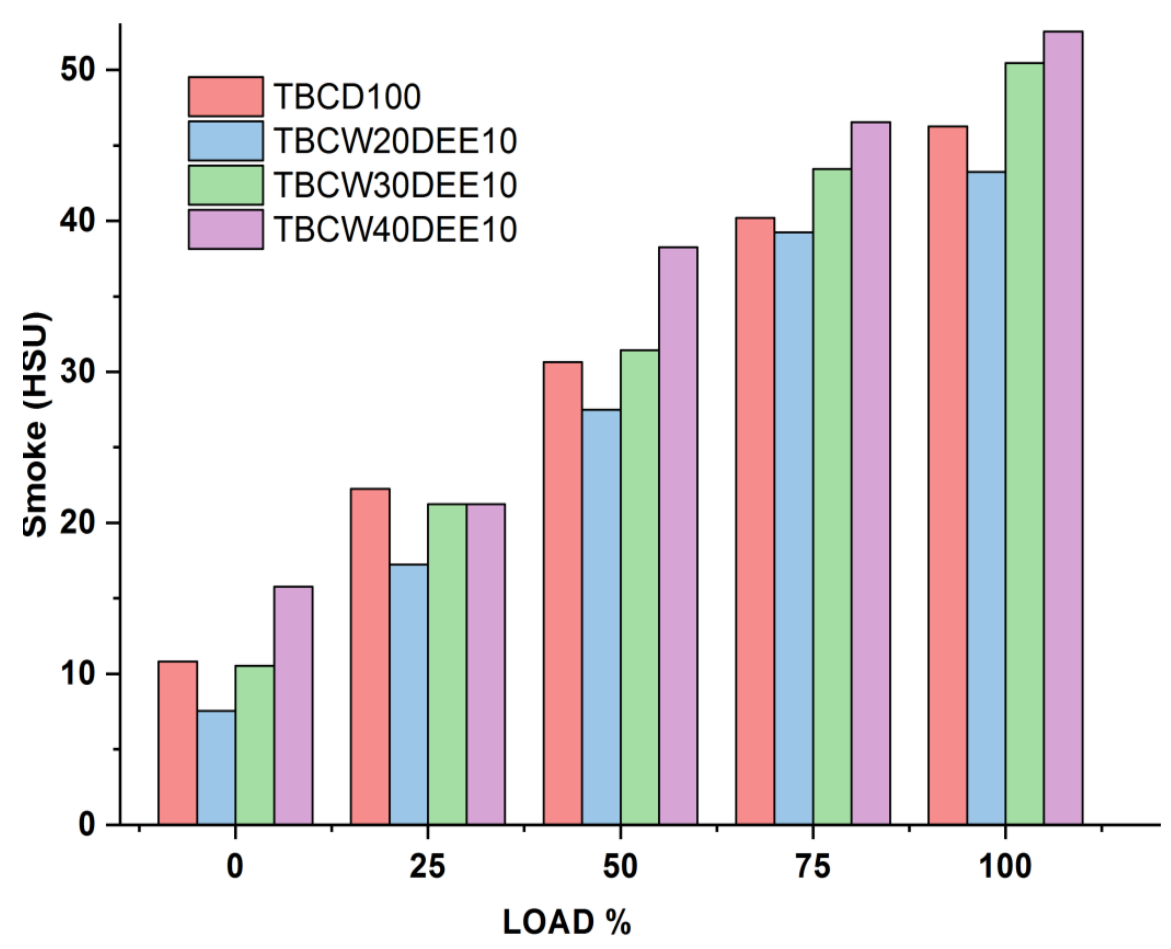

Fig. 6: Evaluation of WPPO's smoke on engine load. 


\section{CONCLUSION}

Consumable plastic materials accumulate during daily operations, and the world is yet to develop a better method of disposing of non-biodegradable plastics. The most difficult aspect of waste plastic recycling is that it may be converted into electricity. The primary purpose of this study is to demonstrate the feasibility of using WPPO as an alternate energy source in the automotive industry. To address the high-value emissions of WPPO in a diesel engine, a thermal barrier coating was created as a test rig for the evaluation of exhaust pollution reduction and engine performance enhancement, resulting in lower fuel consumption. On the TBC engine's WPPO blends, the following observations were made: At different load conditions, TBCW20DEE10's specific fuel consumption decreases by approximately $1.5 \%$ to $7.5 \%$. At the maximum load, WPPO blends increased the thermal performance achieved the nearer to the value of Diesel. TBCW20DEE10 demonstrated an increase in carbon monoxide elimination of between 5 to $15 \%$ under different load conditions. For different load conditions, TBCW20DEE10 demonstrated a greater reduction of hydrocarbons varying from $5 \%$ to $12 \%$. At half load condition, TBCW20DEE10 emits approximately $3.5 \%$ less unit of smoke. On this evaluation, based on the results, WPPO can be utilized as an alternative energy source for fossil fuels.

\section{REFERENCES}

Aydin, S., C. Sayin, and H. Aydin. 2015. Investigation of the usability of biodiesel obtained from residual frying oil in a diesel engine with a thermal barrier coating. Applied Thermal Engineering, 80: 212-219.

Bridjesh, P., Periyasamy, P., Chaitanya, A.V.K. and Geetha, N.K. 2018. MEA and DEE as additives on diesel engines using waste plastic oil diesel blends. Sustain. Environ. Res., 28(3): 142-147.

Damodharan, D., Sathiyagnanam, A.P., Rana, D., Kumar, B.R. and Saravanan, S. 2017. Extraction and characterization of waste plastic oil (WPO) with the effect of $n$-butanol addition on the performance and emissions of a DI diesel engine fueled with WPO/diesel blends. Energy Conv. Manage., 131: 117-126.

Das, A.K., Hansdah, D., Mohapatra, A.K. and Panda, K. 2020. Energy, exergy, and emission analysis on a DI single-cylinder diesel engine using pyrolytic waste plastic oil diesel blend. J. Energy Inst., 93(4): 1624-1633.

Gnanamoorthi, V. and Jayaram, M. 2019. Experimental investigation of $\mathrm{A} 12 \mathrm{O} 3 / 8 \mathrm{YSZ}$ and CeO2/8YSZ plasma sprayed thermal barrier coating on the diesel engine. Ceramics Int., 4(3): 3166-3176.

Gungor, C., Serin, H., Ozcanli, M., Serin, S. and Aydin, K. 2015. Engine performance and emission characteristics of plastic oil produced from waste polyethylene and its blends with diesel fuel. Int. J. Green Energy, 12(1): 98-105.

Hariram, V., Balakarthikeyan, N., Seralathan, S. and Micha Premkumar, T. 2020. Effect of variable compression ratios on performance and emission phenomena of DI CI engine fuelled with palm stearin biodiesel-diesel blends. Nature Environ. Pollut. Technol., 19(4): 1517-1526.

Hariram, V. Seralathan, S. and Mohammed Raffiq, A. 2017. Formulation and characterization of pyrolytic oil from waste tire and waste plastic: a comparative study. Nature Environ. Pollut. Technol., 16(4): 1183-1188.

Hoang, A.T. and Pham, V.V. 2019. Impact of Jatropha oil on engine performance, emission characteristics, deposit formation, and lubricating oil degradation. Combustion Sci. Technol., 191(3): 504-519.

Joel, C., Anand, S., Padmanabhan, S. and Prasanna Raj Yadav, S. 2018. Thermal analysis of carbon-carbon piston for commercial vehicle diesel engine using CAE tool. Int. J. Amb. Energy, 42(2): 163-167.

Mangesh, V.L., Sambandam, P., Tamizhdurai, P., Narayanan, S. and Ramesh, A. 2020b. Combustion and emission analysis of hydrogenated waste polypropylene pyrolysis oil blended with diesel. J. Hazard. Mater., 386: 121453.

Mangesh, V.L., Padmanabhan, S., Tamizhdurai, P. and Ramesh, A. 2020a. Experimental investigation to identify the type of waste plastic pyrolysis oil suitable for conversion to diesel engine fuel. J. Cleaner Prod., 246: 119066.

Mangesh, V.L., Padmanabhan, S., Ganesan, D., Prabhudev, R. and Dinesh Kumar Reddy, T. 2017. Prospects of pyrolysis oil from plastic waste as fuel for diesel engines: A review. IOP Conf. Ser.: Mater. Sci. Eng., 197: 012027.

Mani, M., Nagarajan, G. and Sampath, S. 2011. Characterization and effect of using waste plastic oil and diesel fuel blends in compression ignition engine. Energy, 36(1): 212-219.

Nam Cao, D., Hoang, A.T., Luu, H.Q., Bui, V.G. and Huong Tran, T.T. 2020. Effects of injection pressure on the NOx and PM emission control of diesel engine: A review under the aspect of PCCI combustion condition. Energ. Sources Part A - Recovery Utilization Environ. Effects, 15: 1-18.

Patnaik, P.P., Jena, S.P., Acharya, S.K. and Das, H.C. 2017. Effect of $\mathrm{FeCl} 3$ and diethyl ether as additives on compression ignition engine emissions. Sustain. Environ. Res., 27(3): 154-161.

Rajan, K., Mishra, M.K., Singh, S.K. and Kumar, A. 2016. Experimental evaluation of waste plastic oil and its blends on a single-cylinder diesel engine. J. Mech. Sci. Technol., 30: 4781-4789.

Ramalingam, S., Rajendran, S. and Ganesan, P. 2016. Performance improvement and emission control in a direct injection diesel engine using nanocatalyst coated pistons. Biofuels, 7(5): 529-535.

Sachuthananthan, B., Krupakaran, R.L. and Balaji, G. 2019. Exploration on the behavior pattern of a DI diesel engine using magnesium oxide nano additive with plastic pyrolysis oil as an alternate fuel. Int. J. Amb. Energy, 12: 44-59.

Sambandam, P., Venu, H. and Narayanaperumal, B.K. 2020. Effective utilization and evaluation of waste plastic pyrolysis oil in a low heat rejection single-cylinder diesel engine. Energ. Source Part A- Recovery, Utilization Environ. Effects, 18: 34-53

Singh, R.K., Biswajit Ruj, A.K., Gupta, S.P. and Tigga, V.P. 2020. Waste plastic to pyrolytic oil and its utilization in CI engine: Performance analysis and combustion characteristics. Fuel, 262: 116539.

Sivakumar, E. and Bridjesh, P. 2019. Utilization of unattended waste plastic oil as fuel in low heat rejection diesel engine. Sustain. Environ. Res., 29: 2.

Sivakumar, G. and Senthil Kumar, S. 2014. Investigation on the effect of Yttria stabilized zirconia coated piston crown on performance and emission characteristics of a diesel engine. Alex. Eng. J., 53 (4): 787-794.

Thibblin, A., Jonsson, S. and Olofsson, U. 2018. Influence of microstructure on thermal cycling lifetime and thermal insulation properties of yttria-stabilized zirconia thermal barrier coatings for diesel engine applications. Surf. Coat. Technol., 350: 1-11. 